\title{
Não História: imagem-tempo
}

\author{
ROGÉRIO REIS CARVALHO MATTOS *
}

\begin{abstract}
RESUMO A fenomenologia procura criar, desde Hegel, um modelo explicativo para a história que esbarra em suas próprias limitações. Forma-se uma teoria sobre as teorias da história, mas que são incapazes, mesmo com toda a sofisticação, de explicar o devir histórico ou a prática da escrita historiadora. É menos em "Tempo e Narrativa" do que em "A memória, a história e o esquecimento" que Paul Ricoeur demonstra as aporias do discurso filosófico frente à plasticidade da produção historiográfica. Mas não está em jogo as velhas celebrações a respeito da historiografia francesa, dos Annales. O que se destaca é o entrecruzamento entre o que Deleuze, ao ler Bergson, entende por "objeto real” compreendido como "imagem-cristal” ou "descrição cristalina”, onde o real e o imaginário, o presente e o passado, o atual e o virtual são indiscerníveis, duplas por natureza. O que se pergunta com esta investigação não é apenas o que é o objeto da história, mas qual sua natureza, como ele funciona ao se traçar uma zona de indiscernibilidade em que se pode perguntar como se pensa a história e fazer o inventário de sua escrita, ao se perguntar qual a natureza do documento historiográfico ou das perguntas que levam a se realizar uma pesquisa histórica.
\end{abstract}

PALAVRAS-CHAVE teoria da história, história da filosofia, cinema, literatura

\section{AS APORIAS DO TEMPO}

“O que é então o tempo? Se ninguém me pergunta, eu sei, mas se alguém fizer a pergunta e eu quiser explicar, não sei mais”. A frase de Agostinho, quase todo o tema do livro de Paul Ricoeur Tempo e Narrativa, seria o dilema de cada historiador, para além de qualquer entrevista "fenomenologia do tempo", como acredita-se. Apesar de con-

* Doutorando em Literatura Comparada pela Universidade Federal Fluminense (UFF) Bolsista Capes (Proex) 
trapor Aristóteles a Agostinho, Kant e Husserl a Bergson, fica claro, principalmente quando seguimos a leitura do livro mencionado ao Memória, história, esquecimento, que é inviável uma apreensão fenomenológica do tempo. Suas análises, extensas, sobre o "historial" em Heidegger, por exemplo, acabam por ser conclusivas a respeito: de um lado, ou historiador é quem faz o funeral, quem dispõe do que não tem mais vida, ou ele é o juiz, quem encerra com um julgamento o fato acontecido. Por outro lado, a filosofia de Husserl mostra-se não apenas inconclusiva (devido ao caráter fragmentário de sua obra), mas afeita a toda espécie de aporias. Não se consegue criar o método para a apreensão do ser-em-si do passado, dado que a abordagem da fenomenologia o compreende como uma espécie de coisa, de objeto concreto, que deve ser reconstituído de modo que deva ser apreensível pelos olhos, pelos sentidos. Esta é a armadilha que a filosofia bergsoniana escapa com toda uma outra concepção do que seria o “objeto real”, posteriormente melhor elaborada por Gilles Deleuze com seu conceito de Imagem-tempo.

Em termos bergsonianos, o objeto real reflete-se numa imagem especular tal como no objeto virtual que, por seu lado e ao mesmo tempo, envolve ou reflete o real: há "coalescência” entre os dois. Há formação de uma imagem bifacial, atual e virtual. É como se uma imagem especular, uma foto, um cartão-postal, se animassem, ganhassem independência e passassem para o atual, com o risco de a imagem atual voltar ao espelho, retomar lugar no cartão-postal ou na foto, segundo um duplo movimento de liberação e de captura. (...)

A imagem-cristal, ou a descrição cristalina, tem mesmo duas faces que não se confundem. É que a confusão entre real e imaginário é um simples erro de fato, que não afeta a discernibilidade deles: a confusão só se faz "na cabeça” de alguém. Enquanto a indiscernibilidade constitui uma ilusão objetiva; ela não suprime a distinção das duas faces, mas torna impossível designar um papel e outro, cada face tomando o papel de outra numa relação recíproca, ou de reversibilidade. Com efeito, não há virtual que não se torne atual em relação ao atual, com este se tornando virtual sob esta mesma relação: são um o avesso e um direito perfeitamente reversíveis. São “imagens mútuas”, como diz Bachelard, nas quais se efetua uma troca. A indiscernibilidade do real e do imaginário, ou do presente e do passado, do atual $e$ do virtual, não se produz, portanto, de modo algum, na cabeça ou no espírito, mas é o caráter objetivo de certas imagens existentes, duplas por natureza ${ }^{1}$.

1 DELEUZE, 2007, p. 87-9 
A “descrição cristalina” nomeada por Deleuze se refere ao pequeno circuito do virtual ao atual, ou vice-versa, provocada por uma mera imagem que faz revolver camadas cada vez mais vastas da realidade, da memória ou do pensamento. É a mesma provocação, pequena provocação, causada pela madeleine em Proust e que o faz ser um mestre da descrição. Tais dados, mínimos, que se aproximam de nós quase por acaso, nos provocam a necessidade de contar uma história, nos faz ser tomados quase que por uma espécie de nostalgia: imagem bifacial que torna indiscernível o passado e o presente, o virtual e o atual, o real e o imaginário. Daí a impossibilidade fenomenológica ou o estupor de santo Agostinho ao ser questionado a respeito da existência do tempo. O caráter objetivo das imagens aparece antes em sua duplicidade do que numa suposta objetividade, quase tactibilidade, ou seja, no sensualismo que Husserl tentou fazer inutilmente ser a marca do "passado enquanto tal", devidamente submetido ao escrutínio do olho humano como numa grande mesa de anatomia. As imagens-cristal, as imagens-mútuas, ao nos olharem, ao fazer nos sentir olhados por algo até então inanimado - mais um objeto levado à superfície pelo tempo, uma foto, um cartão-postal -, é como o jogo de dados que se apresentam subitamente à consciência. Não podemos saber em certos momentos se somos assaltados, por assim dizer, pela memória, pelo pensamento que temos a respeito de determinada coisa (quando sentimos que tais e quais pensamentos, memórias, etc., não estão adequadamente em seus lugares de costume), ou quando algo não menos concreto, o real e não nosso imaginário, nos apresenta uma outra ordem dos fatos. De qual tempo se trata?, perguntará Agostinho.

O frei não vê o tempo como Aristóteles ou Kant, porque para ele o tempo não está subordinado ao movimento, mas o contrário. Estudar o cinema é fazer pura arqueologia, para além de quaisquer demarcações críticas. No trabalho de Deleuze não é a passagem do cinema mudo ao falado, da imagem-tempo para a imagem-movimento que interessa enquanto um tipo específico de história, a do cinema, mas a distinção entre dois modos diversos de se perceber as imagens. A imagem de Agostinho diante do tempo pode ser descrita de acordo com a linguagem cinematográfica utilizada por Deleuze:

De repente as situações já não se prolongam em ação e reação, como exigia a imagem-movimento. São puras situações óticas e sonoras, nas quais a personagem não sabe como responder, espaços desativados nos quais ela deixa de sentir e de agir, para partir para a fuga, a perambulação, o vaivém, vagamente 
indiferente ao que lhe acontece, indecisa sobre o que é preciso fazer. Mas ela ganha em vidência o que perde em ação e reação: ela VÊ, tanto assim que o problema do espectador torna-se “o que há para se ver na imagem?” (e não mais “o que veremos na próxima imagem?”). A situação já não se prolonga em ação por intermédio de afecções. Está cortada de todos os seus prolongamentos, só vale por si mesma, tendo absorvido todas as suas intensidades afetivas, todas suas extensões ativas. Já não é uma situação sensório-motora, mas uma situação puramente ótica e sonora, na qual o vidente substitui o actante: uma “descrição" 2 .

Este o ethos de Proust, por sinal. O esplendor da imagem clássica, a que a fenomenologia em vão tentava colocar como forma perene, se deu num sistema geral de comensurabilidade, de medição, aferição; por isso, sua escravidão ao olho. Entre o intervalo e o todo, sua aporia: não conseguir restituir um com o outro, a busca em vão da materialização do que já se foi. Não por outro motivo a imagem-tempo matou o flash-back, a voz em off, o extracampo: as explicações extrínsecas que tentam encadear Cronos sob a ameaça do Aion. A história do cinema é uma prática dos conceitos. "Uma teoria do cinema não é 'sobre' o cinema, mas sobre os conceitos que o cinema suscita, e que eles próprios estão em relação com outros conceitos que correspondem a outras práticas, não tendo a prática dos conceitos em geral qualquer privilégio sobre as demais, da mesma forma que um objeto não tem sobre os outros 3 " Assim, aplicamos seus conceitos em outras práticas como as da historiografia quanto a da literatura ou da filosofia. Bergson, na Evolução Criadora, batiza de ilusão cinematográfica uma ilusão tão antiga quanto os paradoxos de Zenão, o que o afasta da fenomenologia, segundo a qual os efeitos do cinema nos afastam de nossa percepção natural. Teríamos todos um “cinematógrafo interior”, um dispositivo interno acionado seja pela percepção, pela intelecção ou pela linguagem. Trata-se, portanto, de formas de olhar, seja em Husserl ou no historial hedeggeriano, ou nos signos cinematográficos de Bergson e Deleuze.

Por formas de olhar, nos remetemos a François Hartog, que tanto e tão bem escreveu sobre o tema. Em seu Regimes de historicidade 4 , diz que Ulisses não leu santo Agostinho. O primeiro não tinha a noção exata do que seria o ordenamento entre passado, presente e futuro. Quando chora Ítaca não chora por um tempo por vir. Ele tem ape-

DELEUZE, 2007, p. 323

3

4 HARTOG, 2014 
nas a distensio, como nomeada no capítulo 28 das Confissões, incapaz de dar atenção à expectativa do tempo vindouro, ou seja, àquilo que dedicamos nossa atenção. O jogo entre attentio e distensio é a tensão que se coloca na história e foi tão bem elaborada por Ricoeur, algo que não se tinha a exata noção nos tempos antigos. A falta de consciência a respeito do porvir, este entendido no sentido mais largo de sua acepção, seria a característica da Antiguidade, o que supostamente faria o ser antigo encarar a história dentro da concepção dos ciclos. Arnaldo Momigliano entrevê uma possível antecipação do que se tornaria a chamada filosofia da história quando diz que o "Império Romano tornou possível escrever história universal 5". O historiador italiano gostaria de provar que os filósofos gregos é que pensavam em termos cíclicos e não os historiadores. Seu maior exemplo seria Políbio. Seu modelo de história das constituições, contudo, é o que o faz estacar na afirmativa. Existiria uma clara influência filosófica, ainda que não objetivamente detectável. Como as linhas que dividem os saberes não são deveras claras como se quer na ciência moderna, Políbio foi talvez o maior historiador romano; porém, por esta mesma influência grega que tanto prezava, também foi dublê de filósofo, com o destino particular de ter ficado conhecido mais por suas análises das constituições, ou seja, supostamente sobre as histórias cíclicas, do que propriamente por seu trabalho de historiador. Contudo, à margem de qualquer influência filosófica ou não, a discussão sobre as Constituições era um topos historiográfico desde Heródoto e não especificamente trabalho da filosofia. Pelo contrário, a definição da constituição correta ou ideal foi um trabalho contínuo por parte dos historiadores.

Momigliano consegue concluir que "o progresso ilimitado talvez não seja um conceito grego, mas o progresso ilimitado é um desses conceitos que poucas vezes teve muita importância para os historiadores. O que mais importa é que os historiadores gregos reconheciam um progresso contínuo, ainda que limitado, na esfera da filosofia, da ciência, das artes e das constituições, antes que nas ações morais e políticas comuns ${ }^{6 "}$. Políbio, que desempenhou para Cipião Emiliano um papel como o de Sócrates para Alcebíades, estava ainda com seu amado vinte anos depois contemplando o incêndio de Cartago. “Com lágrimas no olhos, 'chegando-se a mim e tomando-me 
a mão', Cipião disse: 'É um momento glorioso, Políbio, mas tenho o pressentimento sombrio de que em algum dia a mesma condenação cairá sobre minha própria pátria 7". O Império Romano permite o advento de uma história universal, o pressuposto da filosofia da história. Porém, guarda em si mesmo as raízes de sua destruição. O eterno retorno novamente lançará seus fados, talvez não aja solução de continuidade. Esta a imbricação entre espaço de experiência e horizonte de expectativa no mundo helenístico. As duas Guerras Púnicas, o papel de liderança assumido por Roma no Mediterrâneo, fez alargar o “espaço da experiência”, como definido por Koselleck, do historiador romano, do mundo helenístico de um modo geral, ainda que este espaço permanecesse limitado pela natureza. Ainda que os romanos possam ter vislumbrado um "horizonte de expectativas" nunca antes imaginado depois da conquista do norte da África e o domínio sobre os mares, estavam bastante longe da filosofia da história, como apontado acima por Momigliano ou do conhecimento histórico propriamente moderno, como entende Koselleck, ou seja, a partir da distinção do que é o domínio da técnica e o que pertence à natureza.

As categorias temporais formais, acima citadas, são parte da forma de pensar dos antigos gregos. Ainda que, sob essa perspectiva, a história [Historie], como disciplina e investigação (para falarmos como Christian Meier) tenha por objeto tudo o que diz respeito aos homens, ultrapassando, dessa forma, o domínio daquilo que foi mais tarde efetivamente designado como histórico [Geschichtlichen], ela pode muito bem comportar a distinção entre decursos temporais irreversíveis e períodos de tempo determinados pelo “destino" histórico. De forma implícita, os antigos desenvolveram teoremas sobre determinados lapsos de tempo dentro dos quais era possível pensar a mudança constitucional, ainda que sob circunstâncias já dadas. Trata-se de tempos de qualidade histórica, certamente condicionados pela natureza e que, por conta disso, permanecem ligados a ela, mas cujas estruturas genuínas já avançam em direção ao conhecimento histórico ${ }^{8}$.

Ulisses pôde, portanto, entrever Agostinho, porém não antecipá-lo. Procede pelo modelo de montagem, decupando as imagens de acordo com suas recordações. É o esquema sensório-motor. Quando chora Ítaca está mais preocupado com as glórias que deixou por lá, com o transcurso ininterrupto do tempo que poderá relegá-las ao

7 MOMIGLIANO, 1997, p. 64

8 KOSELLECK, 2006, p. 125-6 
esquecimento (distensio), do que propriamente com um futuro que deseja seu, com alguma inevitabilidade histórica a ocorrer no futuro, com de alguma forma intervir nesse presente que transcorre sem parar, intervenção esta entrevista no devir a partir da participação da attentio que se presta ao tempo atual, ou seja, de sua comparação não tanto com o passado que se esvai, mas com o futuro que se anseia. Georges Didi-Huberman rompe com a divisão temporal operada por Deleuze entre imagens do movimento e do tempo. O trabalho de montagem seria algo da mais urgente modernidade, como no Atlas de Warburg ou nas máquinas de guerra construídas com recortes dos mais heterogêneos feito por Brecht em sua vivência no exílio, na guerra9 ${ }^{9}$ Toda a sua séria chamada de O olho da história é um pouco a apoteose dessas formações de imagens um tanto mais arcaicas, trazendo-as para o agora, para a teoria do cinema - e das imagens - mais atual. Coloca em paridade, em imagens heautônomas, o que parecia em Deleuze pertencer somente às imagens visuais e as sonoras da Imagem-tempo. Mas esta é toda uma máquina de guerra montada por exemplo por Eisenstein: Chaplin e o cineasta russo acabam por ficar nessa primeira parte da história do cinema, sem adquirir, por exemplo, o destaque dado pelo filósofo a Orson Welles, aquele que fabrica “as potências do falso”. De fato, seguindo cronologicamente sua análise, não é o jogo do real e do imaginário, nem a passagem do virtual para o atual e vice-versa, mas o jogo da verdade, do verdadeiro e do falso, que acaba sendo o fim de sua história, seu grand finale. Nada mais compreensível devido ao seu pioneirismo, e que não desmerecem as análises, os personagens e poemas conceituais que cria nos dois volumes dedicados ao cinema. Mas, colocando a máquina de guerra remontada por Didi-Huberman, o trabalho de Ulisses é o de resistência, trabalho militante, guerreiro, e não a jornada dos sonhos, do Orfeu bem sucedido ao final da sua Busca, como em Proust. Em cada situação, ativar uma ordem diferente, uma linguagem apropriada, para se falar sobre o que se busca. Ulisses deve falar com Agostinho.

Na imagem-cristal de Agostinho, a “plasticidade da ordem cristã do tempo na qual presente, passado e futuro articulam-se na eternidade”, como nomeia Hartog ${ }^{10}$, rompe com os quadros da historia magistra, compondo "uma tensão para o antes e um

9 Faço alusão aqui, de maneira geral, à série composta por mais de seis livros intitulada L'Eil de l'histoire.

10 HARTOG, 2013, p. 92 
'fervor de esperança' voltado para o futuro ${ }^{11}$ " que muito faria dever posteriormente a filosofia da história, tanto quanto a experiência moderna de tempo. Na literatura eclesiástica passa-se a escandir as tensões entre o já e o ainda não, um já que corresponde à vinda de Cristo, um ainda não correspondente aos tempos do Apocalipse, à volta de Cristo. Este tempo se dilatou com o passar dos séculos, permitindo o aparecimento da história feita pela Igreja, sempre ocorrida neste entre-tempo que fazia reatualizar a partir de seus rituais. É digno de nota que na época de Lutero o Apocalipse ainda se mostrava deveras presente no cotidiano das pessoas, podendo o fim dos tempos ocorrer hoje, amanhã ou logo mais, como atestam os próprios escritos do ex-monge agostiniano. Depois, uma laicização, uma secularização das palavras, dos conceitos, ocorreu, o que dilatou ainda mais a distância entre o já e o ainda não religiosos, dentro de uma perspectiva de progresso contínuo, fez substituir a Providência pela capacidade humana de intervenção em seu presente. Os dois tempos se tornam ainda mais prementes, a atenção se desdobra sobre a distensão temporal, devido à capacidade humana de intervenção neste mesmo tempo histórico (espaço de experiência) e da imaginação sobre o que isso pode acarretar (horizonte de expectativas). Jogos do verdadeiro e do falso, cinema de Welles, e não confronto do real com o imaginário, bloqueio nas passagens do virtual ao atual.

Tudo isso para falarmos em termos didáticos. Nootempos.

\section{A HISTÓRIA SOB O SIGNO DE JANO}

Em Bergson ou a Mallarmé os dados jogados são trabalhados pela consciência de maneira a dispô-los convenientemente, apreendidos não em sua materialidade, a partir de bases sensuais meramente. Jano é uma imagem bifronte, um deus por sua própria apresentação, em sua materialidade, pagão. Clio ainda é uma espécie de são Jerônimo pinçada do mundo helenístico, para não dar características demasiado cristãs à tarefa que se quer científica praticada pelos historiadores. Jano, pelo contrário, está no inesquecível quarto comentário a Bergson feito por Gilles Deleuze. Não falamos de história meramente, ou do que se possa entender por ela, mas de Imagens-tempo, cristais, cronosignos que não param de se prolongar em noosignos. Aporias do tempo, necessidades de desvio, tracejado da linha de fuga:

11 HARTOG, 2013, p. 92 
O cristal revela uma imagem-tempo direta, e não mais uma imagem indireta do tempo, faz melhor, reverte sua subordinação em relação ao movimento. $O$ cristal é como um ratio cognoscendi do tempo, e o tempo, inversamente, é ratio essendi. O que o cristal revela ou faz ver é o fundamento oculto do tempo, quer dizer, a sua diferenciação em dois jorros, o dos presentes que passam e o dos passados que se conservam. De uma só vez faz passar o presente e conserva em si o passado. Ambas são complexas, e valem para o conjunto do tempo.

Vimos que Bergson conferia estatuto muito rigoroso à primeira. É o esquema do cone revertido. O passado não se confunde com a existência mental das imagens-lembrança que o atualizam em nós. É no tempo que ele se conserva: é o elemento virtual em que penetramos para procurar a "lembrança pura" que vai se atualizar em uma "imagem lembrança”. E esta não teria sinal algum do passado, se não fosse no passado que tivéssemos ido procurar seu germe. É a mesma coisa com a percepção: assim como percebemos as coisas lá onde elas estão presentes, no espaço, nós lembramos lá onde elas passaram, no tempo, e tanto numa caso quanto no outro saímos de nós mesmos. A memória não está em nós, somos nós que nos movemos numa memória-Ser, numa memória-mundo. Em suma, o passado aparece como a forma mais geral de um já-aí, de uma preexistência em geral, que nossas lembranças supõem, até mesmo a primeira, se uma houvesse, e que nossas percepções, até mesmo a primeira, utilizam. Desse ponto de vista, o próprio presente não passaria sem esta condição. Não passaria, se não fosse o grau mais contraído do passado. Com efeito, é digno de nota que o sucessivo não seja o passado, mas o presente que passa. O passado, ao contrário, se manifesta como a coexistência de círculos mais ou menos dilatados, mais ou menos contraídos, cada um dos quais contém tudo ao mesmo tempo, e sendo o presente o limite extremo (o menor circuito que contém todo o passado). Entre o passado como preexistência em geral e o presente como passado infinitamente contraído há, pois, todos os círculos do passado que constituem outras tantas regiões, jazidas, lençóis estirados e retraídos: cada região com seus caracteres próprios, seus “tons”, “aspectos”, “singularidades”, “pontos brilhantes”, "dominantes". Conforme a natureza da lembrança que procuramos, devemos saltar para este ou aquele círculo. Claro, tais regiões (minha infância, minha adolescência, maturidade etc.) parecem se suceder. Porém, ela só se sucedem do ponto de vista dos antigos presentes que marcaram o limite de cada uma. Inversamente, elas coexistem, do ponto de vista do atual presente que cada vez representa o seu limite comum, ou a mais contraída dentre elas. O que Fellini diz é bergsoniano: "somos construídos como memória, somos a um só tempo a infância, a adolescência, a velhice e a maturidade". O que acontece quando procuramos uma lembrança? Precisamos nos instalar no passado em geral, depois 
temos de escolher entre regiões: em qual delas acreditamos estar escondida a lembrança, escolhida, esperando por nós, se esquivando? (Será um amigo de infância ou de juventude, da escola ou do serviço militar...?) Precisamos saltar para uma região escolhida, ainda tendo a possibilidade de retornar ao presente para dar outro salto, se a lembrança procurada não nos responde e não vem se encarnar numa imagem-lembrança. Tais são os caracteres paradoxais de um tempo não cronológico: a preexistência de um passado em geral, a coexistência de todos os lençóis do passado, a existência de um grau mais contraído. É a concepção que será encontrada no primeiro grande filme de um cinema do tempo, Cidadão Kane, de Welles.

E, em Bergson, essa imagem-tempo se prolonga naturalmente numa imagem-linguagem e numa imagem-pensamento. O que o passado é para o tempo, o sentido é para a linguagem, e a ideia para o pensamento. O sentido como linguagem é a forma de sua preexistência, aquilo em que nos instalamos já de início para compreender as imagens em frases, para distinguir as imagens de palavras e até de fonemas que ouvimos. Por isso ele se organiza em círculos coexistentes, lençóis ou regiões, entre os quais escolhemos conforme os signos auditivos atuais confusamente compreendidos. Do mesmo modo, instalamo-nos já de início na ideia, saltamos para este ou aquele de seus círculos a fim de formar imagens que correspondem à investigação atual. Assim, cronosignos não param de se prolongar em lektosignos, em noosignos.

Mas, conforme outra vertente, pode o presente valer, por sua vez, pelo conjunto do tempo? Talvez sim, se conseguirmos destacá-lo de sua própria atualidade, exatamente como distinguimos o passado da imagem-lembrança que o atualizava. Se o presente se distingue atualmente do futuro e do passado é porque é presença de alguma coisa, que justamente deixa de ser presente ao ser substituído por outra coisa. É em relação ao presente de outra coisa que o passado e o futuro se dizem passado e futuro de uma coisa. Vamos passando portanto ao largo de acontecimentos diferentes, conforme um tempo explícito ou uma forma de sucessão que faz com que coisas diversas ocupem uma após a outra o presente. O mesmo já não ocorre se nos instalamos no interior de um único e mesmo acontecimento, se nos embrenhamos no acontecimento que se prepara, acontece e se apaga, se substituímos a vista pragmática longitudinal por uma visão puramente ótica, vertical, ou antes, em profundidade. $\mathrm{O}$ acontecimento não se confunde mais com o espaço que lhe serve de lugar, nem com o atual presente que passa: "a hora do acontecimento termina antes que termine o acontecimento, o acontecimento começará então em outra hora (...); todo o acontecimento está por assim dizer no tempo em que nada passa", e é no tempo vazio que antecipamos a lembrança, desagregamos o que é atual e situamos a 
lembrança uma vez formada.Desta feita não há mais futuro, presente e passado sucessivos, segundo a passagem explícita dos presentes que discernimos. $\mathrm{Na}$ bela fórmula de Santo Agostinho, há um presente do futuro, um presente do presente, um presente do passado, todos eles implicados e enrolados no acontecimento, portanto, simultâneos, inexplicáveis. Do afeto ao tempo: descobrimos um tempo interior ao acontecimento, que é feito da simultaneidade dos três presentes implicados, dessas pontas de presente desatualizadas. É a possibilidade de tratar o mundo, a vida, ou simplesmente uma vida, um episódio, como único e mesmo acontecimento, que funda a implicação dos presentes. Um acidente vai acontecer, acontece, aconteceu; mas também é ao mesmo tempo que ele vai ocorrer, já ocorreu, está ocorrendo; de modo que, devendo ocorrer, ele não ocorreu, e, ocorrendo, não ocorrerá... etc. É o paradoxo da camundonga Josefina, em Kafka: ela canta, cantou, cantará, ou então nada disso, embora tudo isso produza diferenças inexplicáveis no presente coletivo dos camundongos? É ao mesmo tempo que alguém não tem mais a chave (quer dizer que a tinha), ainda a tem (não a havia perdido) e a encontra (quer dizer, ele a terá e não a tinha). Duas pessoas se conhecem, mas já se conheciam e não se conhecem ainda. A traição se faz, nunca se fez e, no entanto, se fez e se fará, ora num traindo o outro, ora o outro primeiro, tudo de uma vez. Encontramo-nos aqui numa imagem-tempo direta de outra natureza que a precedente: não mais a coexistência dos lençóis do passado, mas a simultaneidade das pontas de presente. Temos portanto duas espécies de cronosignos: os primeiros são aspectos (região, jazida), os segundos são acentos (pontos de vista) ${ }^{12}$.

Exatamente como falamos mais na primeira seção deste artigo: o aturdimento ao estilo de Agostinho ocorre quando somos pegos de surpresa por pensamentos, lembranças ou memórias que parecem não mais se encontrarem no seu lugar de conforto, ou seja, houve um revolvimento geológico interno que sacudiu os diversos extratos do tempo que amparam nossa vida, e que podem mudar completamente seu aspecto; de outro, de acordo com as percepções que nos chegam do mundo, os acentos diferentes que nos ferem - uma questão musical por excelência - que não faz mais remexer os lençóis do passado, mas sacudir as pontas do presente. É o paradoxo de Josefina, a prática historiadora, que tenta criar seu arranjo - sempre de maneira literária, em forma literária, para lembrar Ricoeur ou Benedetto Croce - a simultaneidade apresentada pelas pontas de presente quando somos tomados pelos acentos que ouvimos mais ali, em uma outra coisa, num presente que não é o nosso. Quando assumimos 
uma posição puramente ótica, vertical, como em Husserl; ao procurar captar o que a fenomenologia tem de mais pomposo, sua suposta profundidade, perdemos a noção de espaço, de geo-história, algo fundamental para se entender o conceito de Deleuze e Guattari no O que é a filosofia? quando falam a respeito do Acontecimento, por exemplo. É quando eles conseguem explicar as aporias de Arnaldo Momigliano: “a história da filosofia, na Grécia, não deve esconder que os gregos sempre tiveram primeiro que se tornar filósofos, do mesmo modo que os filósofos tiveram de se tornar gregos ${ }^{13}$ ". Já que os gregos primeiro deveriam se tornar filósofos, assim como o contrário na época da filosofia da história, na era moderna da historiografia, Heródoto, Plutarco ou qualquer outro "historiador de ofício", se é que podemos denominar os historiadores antigos desta maneira. Como Husserl, “Hegel e Heidegger permanecem historicistas, na medida em que tomam a história como uma forma de interioridade, na qual o conceito desenvolve ou desvela necessariamente seu destino. A necessidade repousa sobre a abstração do elemento histórico tornado singular ${ }^{14 " . ~ P a r a ~ r e t o r n a r ~ a ~}$ Momigliano, o progresso ilimitado não é um conceito grego e, de todo modo, nunca foi um conceito dos historiadores. Logo, com Deleuze e Guattari, vemos que a filosofia da história é um conceito particular de determinados filósofos. Existiria talvez algo novo nisto caso comparemos as filosofias da história mais modernas, como a que dita o fim dos tempos, principalmente após a queda do muro de Berlim... O mundo liberal que se impõe guardaria a constituição mais perfeita, não precisando mais de se voltar a antigas formas ou se especular a respeito dela. Está imposto - e ponto final. É quando o horizonte de expectativas se reduz a tal ponto que delimita um campo de experiência ilimitado. Infinidade não mais no conceito, no porvir, mas na experiência de se viver um mundo definitivamente, e irrevogavelmente (assim acharam os neoliberais), pós-histórico e com muita "liberdade de comércio". Ao contrário de Políbio ao lado de Cipião ao assistir o incêndio de Cartago, não puderam prever a inevitável ou a mais do que possível ruína do Império que poderia fazer visualizar uma história sem fim... A queda do muro de Berlim, caso seja um correlato longínquo do incêndio de Cartago, encontrou homens muito, mas muito, menores do que os da Antiguidade.

13 DELEUZE; GUATTARI, 2010 b, p. 115

14 DELEUZE; GUATTARI, 2010 b, p. 115 
Existe em Deleuze quase uma indistinção entre os campos da filosofia e os da historiografia. Fica claro quando ele pensa sobre o tempo em Bergson. Talvez fique mais claro ainda quando - conceito recorrente - remete à necessidade de uma geo-história ou de uma geofilosofia. Veremos a seguir qual relação este conceito guarda com o de imagem-tempo ou o de cristais.

A filosofia é uma geofilosofia, exatamente como a história é uma geo-história, do ponto de vista de Braudel. Por que a filosofia na Grécia em tal momento? Ocorre o mesmo com o capitalismo, segundo Braudel: por que o capitalismo em tais lugares e em tais momentos, por que não na China em tal outro momento, já que tantos componentes já estavam presentes lá? A geografia não se contenta em fornecer uma matéria e lugares variáveis para a forma histórica. Ela não é somente física e humana, mas mental, como a paisagem. Ela arranca a história do culto da necessidade, para fazer valer a irredutibilidade da contingência. Ela arranca do culto das origens, para afirmar a potência de um "meio" (o que a filosofia encontra entre os gregos, dizia Nietzsche, não é a origem, mas um meio, um ambiente, uma atmosfera ambiente: o filósofo deixa de ser um cometa...). (...). Não se pode reduzir a filosofia a sua própria história, porque a filosofia não cessa de se arrancar dessa história para criar novos conceitos, que recaem na história, mas não provém dela. Como algo viria da história? Sem a história, o devir permaneceria indeterminado, incondicionado, mas o devir não é histórico. Os tipos psicossociais são da história, mas os personagens conceituais são do devir. O próprio acontecimento tem necessidade do devir como de um elemento não histórico ${ }^{15}$.

A filosofia aparece na Grécia por causa deste devir e não por causa de uma história, por causa de uma geografia e não de uma historiografia, de um momento intempestivo e não por um trabalho da natureza. Falaremos, sobrepondo nossa voz a de Deleuze que, não exatamente a partir de um retorno a Nietzsche (para onde voltaremos, entretanto), mas de uma aproximação da história com a filosofia, do pensamento com a pesquisa empírica, é que encontramos modelo de Jano, para além de Clio: o passado em estado puro assim como a potência do presente, o revolver simultâneo de suas pontas; a duração e a intuição, em termos bergsonianos. O devir e não a história, como dito, as nuvem não históricas, como diz Nietzsche, esse momento da pura duração que lhe joga novamente no vivente, como num lance de dados, a partir da quase indiscernibilidade que encontramos (e aí está o segredo da profunda distinção ope-

15 DELEUZE; GUATTARI, 2010 b, p. 115-6 
rada por Bergson) entre instinto e intuição, sendo este a inteligência daquele: estes o fundamento do conceito de Imagem-tempo, para além de qualquer história, por ser o conceito próprio do que se chamou de o Intempestivo. A fórmula de Groethuysen exposta acima: "a hora do acontecimento termina antes que termine o acontecimento, o acontecimento começará então em outra hora (...); todo o acontecimento está por assim dizer no tempo em que nada passa", eco temas de Bergson e Péguy. Ainda que tenha dado nome a seu livro de Clio, não indica o Cronos, mas o tempo vazio (nuvem não histórica, intempestivo) onde acontece a criação; o mesmo tempo vazio onde, de acordo com a mesma passagem de Deleuze, “antecipamos a lembrança, desagregamos o que é atual e situamos a lembrança uma vez formada". Dá-se o nome de Clio por não se ter ainda imaginação suficiente para dar uma outra imagem à história. Péguy distinguia um tempo histórico longitudinal e uma memória essencialmente vertical - esses os ecos dos dois franceses no "belo texto de Groethuysen”. O quarto esquema do tempo de Berson, como comentado por Deleuze, distingue uma visão espacial que passa ao longo do acontecimento e a visão temporal que se entranha nele. É a distinção que a fenomenologia não soube fazer, sua impossibilidade. Pode-se fazer história com filosofia ou vice-versa, porém é impossível compor uma com a outra a partir dos pressupostos do que os próprios filósofos têm do que seja a filosofia, este meio de interioridade sufocante, este amor pela profundidade, pela verticalidade; igualmente, enquanto se guarde esta "imagem do pensamento" da filosofia e enquanto a história repelir como por demais "fenomenológica” qualquer trabalho que tente pensar um pouco mais seus pressupostos, sem este gosto longitudinal, raso, do puro Cronos, o silêncio do historiador e a solidão do filósofo continuarão a ser incomunicáveis. Mas vamos finalmente chegar a Nietzsche, como dito:

Será preciso dizer que o retorno a Nietzsche implica um certo estetismo, uma certa renúncia à política, um “individualismo” tão despolitizado quanto despersonalizado? Talvez não. A política também é questão de interpretação. O intempestivo do qual falamos há pouco, jamais se reduz ao elemento político-histórico. Porém ocorre às vezes, em momentos grandiosos, que eles coincidam. Quando pessoas morrem de fome na Índia, esse desastre é histórico-político. Mas quando um povo luta por sua libertação, há sempre coincidência entre atos poéticos e acontecimentos históricos ou ações políticas, a encarnação gloriosa de algo sublime ou intempestivo. As grandes coincidências são, por exemplo, a gargalhada de Nasser nacionalizando o canal de Suez, ou sobretudo os gestos inspirados de Castro, e essa outra gargalhada, a de um Giap 
entrevistado pela televisão. Ali, há algo que lembra as injunções de Rimbaud e de Nietzsche e que vem duplicar Marx - uma alegria artista que coincide com a luta histórica. Há criadores em política, movimentos criadores, que por um momento se interpõe na história. Hitler, ao contrário, carecia singularmente do elemento nietzschiano. Hitler não é Zaratustra; e Trujillo taluiza tom jobimmpouco. Eles representam antes o que Nietzsche chama de "o macaco de Zaratustra". Não basta tomar o poder para ser, como diz Nietzsche, um "senhor”. Com frequência são justamente os “escravos” que tomam o poder, e que o mantêm, e que permanecem escravos para preservá- $1 o^{16}$.

Como estamos dizendo desde o início, e agora com a denominação de Deleuze, são dois os noosignos: os aspectos (região, jazida), os segundos são acentos (pontos de vista). Meios internos ou meios externos, longitudinais ou verticais, da história ou da memória. Qualquer um deles pode nos jogar nessa espécie de turvação, aquela mesma sentida por Agostinho quando se perguntou a respeito do tempo. Nada mais do que nuvens não históricas, paisagens. Quando a duração volta ao mundo sensível via intuição, naquela espécie de instinto inteligente, quase não reflexivo, como entendia Bergson, é quando se dá o acontecimento, quando se muda por este Aion os sentidos de Cronos (para não dizer que não nos lembramos da Lógica do sentido). Para se fazer a escrita da história é necessária esta mesma passagem: do turvamento à gargalhada, de Agostinho a Nietzsche. Não como o “macaco de Zaratustra”, porém; muito menos o trabalho subterrâneo, árduo, escondido, do que se entende pelo histórico: um fundo no passado e um decorativo no sótão. Levar para o de profundis e mostrar uma bela e não menos singela decoração... E dizer depois que seu trabalho difere por princípio do que fazem os fenomenólogos, aqueles mestre da profundidade. Mostrar como Aion o que é mero Cronos, no sentido mais simples possível, reles, materialista: fenomenologia, espaço newtoniano, eidética. Apresentar o Cronos na tábua da escrita, tábua das leis, da musa Clio: o Aion em seu aspecto mais rude de mero misticismo, sob a batuta do que seria "fazer história como ciência" (o que, por si só, é um lema para afastar qualquer comparação com a filosofia, ou seja, como cientistas e não filósofos, e estes não como historiadores). No entanto, poucos são capazes tanto dum lado como no outro sentir o aturdimento de Agostinho quando teve de refletir sobre o tempo, muito menos capazes da gargalhada de Nietzsche ao se livrar das trevas do atemporal, das nuvens carregadas (não necessariamente pesadas, mas carregadas, 
por exemplo, de cores, nos paradoxos da cor e do encarnado, como reflete em muitos textos Georges Didi-Huberman ${ }^{17}$ sobre a tarefa das imagens nas artes plásticas), e chegar de fato ao tempo histórico, ou seja, esta ponta de presente, o passado mais distendido, a mera conjuntura, ao instante como no intempestivo - instante do aturdimento, instante da gargalhada, é bom saber distinguir ainda que sob o signo de Jano. Esta a nossa tarefa.

\section{REFERÊNCIAS}

DELEUZE, Gilles. A imagem-tempo. São Paulo: Brasiliense, 2007.

DELEUZE, Gilles. A ilha deserta: e outros textos. São Paulo: Iluminuras, 2006.

DELEUZE, Gilles; GUATTARI, Félix. O que é filosofia?. São Paulo: Editora 34, 2010.

DIDI-HUBERMAN, George. L'image ouverte: motifs de l'incarnation dans les arts visuel. Paris: Gallimard, 2007.

Diante da imagem: questão colocada aos fins de uma história da arte.

São Paulo: Editora 34, 2013.

HARTOG, François. Regimes de historicidade: presentismo e experiências do tempo. Belo Horizonte: Autêntica Editora, 2013.

MOMIGLIANO, Arnaldo. Ensayos de historiografía antigua y moderna. Cidade do México: Fondo de Cultura Económica, 1997. 